\title{
PEMBELAJARAN BIOLOGI BERBASIS PROYEK UNTUK MENGEMBANGKAN SIKAP ILMIAH DAN KESADARAN LINGKUNGAN SISWA SEKOLAH MENENGAH
}

\author{
A. Wahab Jufri \\ Program Studi Pendidikan Biologi FKIP Universtias Mataram \\ awahabjufri@gmail.com
}

\begin{abstract}
Abstrak. Perkembangan ilmu pengetahuan, teknologi dan informasi yang sangat pesat akhir-akhir ini memberikan dampak pada hampir semua aspek kehidupan manusia, termasuk pada masalah lingkungan. Dalam rangka menghadapi permasalahan lingkungan hidup yang sangat kompleks dan multidimensi, pembelajaran biologi memegang peran penting. Model pembelajaran biologi berbasis proyek dapat menjadi salah satu alternatif untuk mengem-bangkan sikap ilmiah dan kesadaran lingkungan di kalangan siswa. Materi pelajaran Biologi dalam pembelajaran berbasis proyek dapat diintegrasikan dengan mata pelajaran lain seperti Bahasa Inggris, Bahasa Indonesia, Matematika, dan IPS. Penugasan siswa untuk mengembangkan proyek-proyek biologi dapat membantu siswa untuk berlatih mengum-pulkan dan menganalisis data, mengidentifikasi variabel, menyelesaikan masalah, dan mengkomunikasikan hasil kerjanya. Melalui kegiatan mengerjakan proyek biologi siswa bahkan dapat berperan merehabilitasi kondisi lingkungan yang terancam rusak. Tentu semua hal tersebut akan dapat berhasil dengan adanya inisiatif, kerja keras, dan kolaborasi antara guru, sekolah, orangtua dan masyarakat.
\end{abstract}

Kata kunci: biologi, proyek, sikap ilmiah, kesadaran lingkungan

\section{TEACHING BIOLOGY AS PROJECT BASED TO HELPIMPROVE SCIENTIFICATTI- TUDES AND ENVIRONMENTALAWARENESS OF SENIOR HIGH SCHOOL STUDENT}

\begin{abstract}
The development of science, technology and information which grow very rapidly nowadays affect almost all aspects of humans life includes the human's environment. In order to solve the very complex and multi dimension environment problems, the teaching of biology plays an important role. Project based model of teaching biology can be an alternative to develop the students scientific attitude and their environment awareness. This model of teaching capable of integrating the subject of biology to other subjects includes English, Indonesian, Mathematics, and Social Science. Student tasks in form of some projects help student to learn by doing through activities of collecting and analyzing data, to identify variables, to solve problems, and to communicate their project results. Furthermore, through project activities, student can involve to rehabilitate the unwanted environmental conditions. Of course, all of those efforts would be useful if there are initiatives, strong efforts, and collaboration between teacher, school staffs, student parents and the communities around the school.
\end{abstract}

Keywords: biology, project, scientific attitude, environmental awareness

\section{I.PENDAHULUAN}

Perkembangan ilmu pengetahuan dan teknologi yang sangat pesat pada abad ke 21 ini, berdampak pada perlunya pergeseran paradigma pembelajaran biologi di sekolah. Pelajaran biologi yang tadinya cenderung bersifat klasikal dan berorientasi pada pengajaran mengenai fakta, konsep, dan hukum-hukum alam sudah saatnya dikembangkan menjadi pola pembelajaran kontekstual melalui pengembangan proyek berbasis inkuiri seperti penyelesaian masalah dan investigasi langsung. Paradigma baru pembelajaran ini merupakan tantangan yang memberikan peluang untuk pengem-bangan profesionalisme guru maupun calon guru biologi. Seiring dengan diberla-kukannya kurikulum tingkat satuan pendidikan (KTSP) yang berorientasi pada pengembangan kompetensi dan kecakapan hidup (life skills) siswa, maka guru dan sekolah secara keseluruhan dituntut untuk terus meningkatkan mutu manajemen dan proses pembelajaran agar dapat tercipta budaya belajar kontekstual yang bersinergi dengan masyarakat atau lingkungan sekitar.

Pengembangan model pembelajaran berbasis inkuiri merupakan salah satu cara untuk menjawab tuntutan tersebut. Dalam pembelajaran dengan model ini, kegiatan pembelajaran dirancang dalam bentuk proyek yang meliputi tugas-tugas kompleks dan dikembangkan berdasarkan pertanyaan-pertanyaan menantang dan mengacu pada masalah-masalah actual di sekitar siswa. Kegiatan pembelajaran melibatkan siswa dalam proses mengidentifikasi masalah, merumuskan hipotesis, 
merancang solusi atau penyelesaian masalah, dan berlatih untuk mengambil keputusan berdasarkan fakta dengan argumentasi yang kuat dan jelas. Keseluruhan rangkaian proses pembelajaran berpusat pada kegiatan belajar siswa (student centered) yang memberikan kesempatan bagi siswa untuk bekerja secara otonom dalam kelompoknya selama periode waktu tertentu sampai mencapai hasil akhir (puncak kegiatan) dalam bentuk produk nyata yang dipertanggungjawabkan melalui proses presentasi [14].

Tantangan yang dihadapi oleh guru dalam pembelajaran berbasis proyek adalah masalah pengaturan waktu dan kesinambungan proses. Guru harus bersedia meluang-kan waktu yang lebih banyak dibandingkan pembelajaran langsung di kelas. Namun dengan mengintegrasikan materi atau hasil kerja proyek ke dalam mata pelajaran lainnya seperti Matematika, Bahasa, dan bidang Sains yang lain, maka masalah ini akan dapat teratasi. Proyek siswa yang dikembangkan dalam pembelajaran inkuiri dapat menjadi lebih efektif jika diintegrasikan dengan model pembelajaran lain misalnya pembelajaran kooperatif [9]. Harus disadari bahwa banyak siswa yang mengalami kendala dengan pembelajaran yang didominasi oleh kegiatan guru (teachercentered). Siswa yang termasuk dalam kelompok seperti ini akan dapat berhasil jika mereka tidak melulu belajar dari apa yang diberikan oleh guru, tetapi mereka akan lebih berhasil jika dapat mendiskusikan informasi-informasi yang relevan dan memani-pulasinya serta berusaha mencocokkanya dengan pengetahuan awal yang sudah mereka miliki.

Pembelajaran biologi yang dirancang dalam kerangka inkuiri untuk mengem-bangkan proyek siswa dan terintegrasi dengan strategi koperatif dapat membantu guru untuk mengkaji dan menyeleksi bagian-bagian penting dari materi pelajaran. Dewasa ini, masih banyak guru biologi yang berusaha menyampaikan fakta dan konsep-konsep baru tanpa berusaha menyeleksi bagian yang urgen dan betul-betul relevan dengan kebutuhan siswa. Akibatnya, materi pelajaran biologi terus bertambah dari waktu ke waktu. [15] menyatakan bahwa lebih dari sepertiga materi pelajaran biologi yang umumnya diajarkan secara tradisional oleh guru sebenarnya dapat menjadi lebih bermakna jika dilakukan dengan latihan-latihan yang menantang siswa untuk belajar mengkonstruksi pengetahuannya sendiri. Penyajian materi pelajaran melaui proyek-proyek yang dikerjakan secara berkelompok dan berpusat pada siswa seperti meng-analisis grafik, membuat peta konsep, dan menjawab pertanyaanpertanyaan menan-tang dapat mengarahkan pembelajaran menjadi lebih bermakna bagi siswa. Penerapan pembelajaran berbasis proyek secara terpadu dengan strategi pembelajaran koperatif melalui model kegiatan inkuiri secara konsisten dan berkesinambungan, diyakini dapat menjadi sarana yang tepat untuk membantu siswa agar memiliki kemampuan berpikir kritis, sikap ilmiah, sadar diri dan sadar lingkungan, serta mampu menerapkan pengetahuannya dalam kehidupan nyata [1] dan [12].

Tema-tema persoalan biologi sekolah menengah, memungkinkan untuk dipelajari melalui keterampilan proses ilmiah yang meliputi observasi, prediksi dan inferensi, menyusun hipotesis, mendesain dan melakukan percobaan, mengidentifikasi variabel, mengumpulkan dan menganalisis data serta mengkomunikasikan hasil kegiatan secara tertulis maupun lisan [2]. Rangkaian kegiatan seperti itu akan dapat dilaksanakan dengan baik melalui sintaks pembelajaran berbasis proyek yang dirancang dengan seksama.

Sebagai ilmu, biologi memiliki obyek kajian berupa mahluk hidup yang tersebar di lingkungan hidup siswa. Lingkungan hidup baik yang bersifat biotik maupun abiotik dewasa ini sedang berada dalam posisi terancam sebagai akibat dari kegiatan eksploitasi lingkungan alam oleh manusia secara langsung maupun tidak langsung. Isu-isu lingkungan seperti pencemaran air, tanah, udara, dan menurunnya keanekaragaman hayati karena terjadinya kepunahan spesies merupakan bagian dari materi pelajaran biologi. Penugasan siswa untuk mengerjakan proyek-proyek biologi sebagai aktivitas inkuiri dapat melibatkan siswa dalam kegiatan langsung menganalisis pencemaran, mendata dan mengidentifikasi jenis mahluk hidup, serta kemungkinan pemeliharaan dan rehabilitasi kualitas lingkungan hidup yang ada di sekitarnya.

Bagian selanjutnya dalam tulisan ini akan membahas jenis-jenis sumber daya dan aspek-aspek lingkungan yang relevan untuk pembelajaran biologi berbasis proyek. Selain itu dibahas pula tentang kemungkinan integrasi hasil kerja proyek ke dalam mata pelajaran lain serta implikasi pembelajaran terhadap sikap ilmiah dan kepedulian siswa terhadap lingkungan.

\section{Pembahasan}

\subsection{Sumberdaya Lingkungan untuk Pembelajaran Biologi Berbasis Proyek}

Lingkungan alam yang ada di sekitar siswa seperti sungai, rawa-rawa, laut, sawah, kebun dan hutan merupakan laboratorium terbuka yang memiliki potensi sangat kaya untuk melatih siswa menerapkan keterampilan proses biologi. Sungai, rawa-rawa dan laut dangkal (pesisir) di negara kita dapat berperan sebagai sarana yang efektif untuk pembelajaran biologi berbasis proyek. Belajar mengumpulkan data tentang kualitas air, identifikasi mahluk hidup akuatik maupun terestrial yang tergantung pada habitat tersebut belum banyak dilakukan oleh siswa sekolah menengah di negara kita. Di negara maju seperti Amerika Serikat, melalui pembelajaran berbasis proyek siswa sudah ikut terlibat dalam kegiatan monitoring kualitas air sungai dan rawa-rawa [8], [11], serta rehabilitasi habitat dan membantu keber-langsungan reproduksi ikan salmon [7]. Di Jepang, bahkan siswa sekolah dasar sudah diberikan tugas tahunan untuk mengumpulkan dan menganalisis kualitas air melalui warna serta keberadaan hewan dan tumbuhan di dalamnya [13].

Kegiatan-kegiatan pembelajaran biologi seperti disebutkan di atas dapat dilakukan atas inisiatif dan kerja keras guru, bahkan atas ide atau usulan dari siswa maupun anggota masyarakat. Melalui pembelajaran langsung di lapangan siswa tidak hanya akan belajar mengenai konsepkonsep biologi semata, tetapi juga sekaligus akan mendapatkan wawasan mengenai masalah-masalah lingkungan yang nyata atau kontekstual. Mungkin akan timbul pertanyaan apakah kurikulum sekolah di Indonesia memungkinkan dilakukannya kegiatan seperti itu? Jawabannya tentu saja mungkin. Bukankah negara kita kaya 
dengan sungai, parit, kolam dan sawah sebagai habitat berbagai jenis ikan, katak dan hewan air lainnya yang bahkan mungkin belum dikenal namanya oleh siswa.

Dalam menghadapi masalah sampah yang sekarang sudah semakin pelik, guru perlu melibatkan siswa dalam kegiatan mengidentifikasi, memilah, bahkan mendaur ulang sampah. Pembuatan kompos misalnya, dapat dilakukan di halaman sekolah atau bahkan di dalam kelas. Dengan berlatih membuat kompos siswa akan belajar tentang konsep pembusukan, fermentasi dan humus.

Kegiatan mengerjakan tugas-tugas berbasis proyek dapat merangsang siswa untuk mengajukan pertanyaan tentang variabel apa saja yang berpengaruh dalam proses pengomposan sampah [4]. Latihan ini dapat dilakukan di halaman sekolah sambil berolahraga, atau bahkan di dalam kelas. Jika kegiatan ini dilakukan dalam konteks pembelajaran berbasis proyek dan terintegrasi dengan mata pelajaran lain, maka siswa tentu akan belajar dengan lebih bersenang hati (joyful learning) sekaligus memberikan pengalaman belajar yang akan terpateri dalam kehidupan selanjutnya (meaningful learning).

\subsection{Aspek-aspek Lingkungan dalam Pembelajaran Biologi Berbasis Proyek}

Seperti telah disebutkan di atas, isu pencemaran air, tanah dan udara merupakan topik bahasan dalam pelajaran biologi di sekolah menengah. Namun kecenderungannya selama ini, guru merasa lebih nyaman menyampaikan materi mengenai definisi pencemaran, macam-macam pencemaran dan sebagainya melalui ceramah di kelas. Siswa sangat jarang diajak melihat langsung bagaimana air yang sudah tercemar, apa yang menjadi sumber pencemaran, dan apa akibatnya bagi mahluk hidup yang ada didalamnya [10]. Untuk belajar mengenai siklus hidup katak, siswa hanya melihat sepintas dari gambar-gambar yang ada di buku teks atau gambar yang diperbesar kemudian dipasang di dinding atau papan tulis. Isu mengenai epidemi demam berdarah sudah merupakan masalah nasional yang tidak asing lagi bagi siswa. Iklan mengenai cara pencegahan penularan penyakit tersebut sering terlihat di televisi dan media lainnya. Tetapi sudah berapa banyakkah guru biologi di sekolah kita yang memfasilitasi siswa untuk mempelajari siklus hidup nyamuk Aedes aegypti yang merupakan agen penyakit tersebut? Pembelajaran berbasis proyek dengan strategi pemecahan masalah, inkuiri dan investigasi sudah diketahui atau paling tidak didengar oleh guru-guru kita, tetapi seberapa seringkah siswa diajak belajar dengan menerapkan strategi tersebut? Banyak siswa yang kadangkadang membantu orangtuanya atau gurunya bekerja di kebun, di sawah atau memelihara ikan di kolam, tetapi apakah mereka sudah memanfaatkan sumber-sumber tersebut untuk lebih jauh mengenal alam lingkungannya? Pertanyaan-pertanyaan seperti di atas merupakan tantangan bagi guru, dosen serta mahasiswa calon guru bidang biologi.

Biologi adalah ilmu yang sangat kaya dengan fakta, konsep, prinsip dan proses-proses yang menarik untuk dikaji. Agar siswa lebih tertarik untuk mempelajari biologi maka guru harus melibatkan mereka dalam proses inkuiri melalui kegiatan bertanya, mencari jawaban pertanyaan, menganalisis data, mendiskusikan ide-ide, dan menerapkan konsep biologi dalam beragam konteks untuk mendeskripsikan dan menjelaskan fenomena [5] dan memberikan pengalaman langsung bagi siswa. Konsepkonsep biologi, kimia dan fisika yang ada dalam konteks lingkungan misalnya benthos, plankton, tumbuhan air, $\mathrm{pH}$, senyawa polutan, kandungan nitrat, posfat, kecerahan, dan suhu merupakan aspek lain yang dapat ditemukan siswa dalam kegiatan proyek biologi. Agar siswa dapat menguasai konsep dengan bermakna (meaningful) dan bertahan lama, maka seharusnya siswa mempelajari dan melakukan kegiatan belajar secara langsung dalam lingkungan yang kontekstual. Kegiatan mengukur, mengamati, menganalisis data dan mendiskusikan apa yang didapatkan melalui proyek biologi, memberi peluang bagi siswa untuk berlatih mengembangkan kompetensi-kompetensi ilmiah seperti kemampuan menguji hipotesis, bekerjasama, dan berkomunikasi baik secara lisan maupun tulisan.

\subsection{Integrasi Proyek Biologi dalam Mata Pelajaran Lain}

Penerapan pembelajaran berbasis proyek, tentu akan menghasilkan data berupa angka-angka dan fakta sebagai hasil pengalaman nyata siswa. Data mengenai aspek-aspek lingkungan yang sudah didapatkan selanjutnya dapat dijadikan bahan pembelajaran untuk mata pelajaran lain seperti Matematika, Bahasa Inggeris, Bahasa Indonesia. Fluktuasi data $\mathrm{pH}$, suhu, kemelimpahan benthos, plankton, dan mahluk hidup lain dapat menjadi bahan ajar yang menarik dalam membahas konsep him-punan, penjumlahan dan pengurangan serta kecenderungan (trend) yang akan terjadi atau probabilitas dalam Matematika. Konsep himpunan tentu akan lebih bermakna jika siswa diminta untuk menghitung junlah anggota himpunan katak, himpunan tanaman, atau himpunan hewan invertebrata yang ada di kebun sekolah.

Hasil pengalaman empiris siswa mengenai kondisi lingkungan tempat ber-langsungnya kegiatan proyek disertai proses pelaksanaannya akan mejadi materi yang menarik untuk memperlancar kemampuan "speaking" siswa dalam pelajaran Bahasa Inggris. Kemampuan menulis ilmiah baik dalam bentuk narasi maupun lambang-lambang seperti grafik dan gambar dalam laporan proyek siswa merupakan kajian yang potensial untuk asesmen kemampuan Bahasa Indonesia siswa. Materi pelajaran lain seperti Sejarah dan Geografi dapat juga diintegrasikan dengan tugas-tugas proyek biologi [4].

Dalam abad 18, ketika di Inggris mulai berkembang industri yang ditandai dengan mengepulnya asap tebal ke angkasa sehingga menyebabkan sinar matahari terhambat sampai di bumi memunculkan permasalahan seperti sesak nafas, epidemi pada manusia, dan pohon-pohon kayu berubah warna menjadi abu-abu kehitaman dan berevolusinya kupu-kupu Biston betularia. Masyarakat ilmiah mulai berpikir untuk membuat peraturan soal lingkungan untuk mengurangi penderitaan. Pelajaran Geografi juga mengandung bahasan mengenai ekosistem hutan tropis yang menjadi paru-paru dunia dan sebagian besar berada di Indonesia untuk kawasan Asia, Brasil untuk kawasan Amerika Latin dan Zaire untuk kawasan Afrika [6]. Ekositem hutan tropis di Indonesia merupakan media yang sangat potensial untuk pembelajaran biologi khususnya bagi sekolah-sekolah yang berada di dekat kawasan hutan. Laut nusantara yang terkenal dengan keanekaragaman ikan 
dan terumbu karangnya juga belum banyak dijadikan sarana pembelajaran biologi. Padahal guru-guru biologi mungkin cukup banyak yang berbicara mengenai kerusakan terumbu karang akibat pengeboman ikan oleh masyarakat pada saat menyajikan topik pembelajaran jenis-jenis pencemaran air.

\subsection{Implikasi Penting dari Pembelajaran Biologi Berbasis} Proyek

V.A. Magnesen menyatakan bahwa manusia belajar $10 \%$ dari apa yang dibaca, $20 \%$ dari apa yang didengar, $30 \%$ dari apa yang dilihat, $50 \%$ dari apa yang dilihat dan didengar, $70 \%$ dari apa yang dikatakan dan $90 \%$ dari apa yang dilakukan dan dikatakan [3]. Berkaitan dengan pendapat tersebut, maka pembelajaran berbasis proyek dapat melatih siswa belajar dengan melakukan secara langsung (learning by doing) dan melaporkan hasilnya secara tertulis maupun lisan. Hal ini berarti termasuk ke dalam bagian terakhir pernyataan Magnesen yakni manusia belajar $90 \%$ dari apa yang dilakukan dan dikatakannya. Dengan melakukan pengukuran dan mengidentifikasi parameter-parameter lingkungan serta bersing-gungan langsung dengan komponen-komponen lingkungan seperti hewan dan tumbuhan serta komponen abiotiknya maka diharapkan akan terbentuk sikap ilmiah dan sikap menghargai objek selain dirinya karena siswa menyadari perannya dalam lingkungan.

Kesadaran akan perannya sebagai pengelola (khalifah) dalam lingkungan, diharapkan dapat menumbuhkan kesadaran lingkungan yang tinggi dan terbentuk sikap peduli terhadap lingkungan dalam kehidupan sehari-hari. Jika siswa sudah memiliki sikap sadar lingkungan, maka dapat diharapkan akan dapat mengajak atau menghimbau orang lain untuk memelihara kualitas lingkungan. Jadi dalam hal ini tugas pokok guru adalah menanamkan sikap sadar lingkungan pada siswa melalui kegiatan mendekatkan siswa dengan lingkungan alam sekitarnya. Pada akhirnya tertitip harapan semoga para pendidik, pemerintah, masyarakat, dan orangtua siswa dapat mendorong serta mendukung terciptanya suasana belajar yang kondusif dan saling mendukung untuk terciptanya lingkungan yang lebih baik dari sekarang serta berperan langsung dalam upaya menjaga keberlangsungan dan keserasian ekosistem bumi.

\section{III.KESIMPULAN.}

Berdasarkan uraian yang telah dipaparkan di atas dapat disimpulkan bahwa pembelajaran biologi dengan model berbasis proyek merupakan salah satu cara yang efektif untuk meningkatkan sikap sadar lingkungan di kalangan siswa. Melalui proyek biologi siswa juga mendapatkan kesempatan belajar untuk mengintegrasikan pengetahuannya dalam beberapa mata pelajaran. Beberapa parameter lingkungan seperti indeks pencemaran, data biota, suhu, kecerahan, jenis polutan dan sebagainya dapat menjadi bahasan yang menarik pada mata pelajaran seperti Matematika, Bahasa Inggris, Bahasa Indonesia, dan IPS khususnya Sejarah dan Geografi.

\section{DAFTAR PUSTAKA}

[1] Depdiknas. 2003a. Kurikulum 2004 SMA Pedoman Khusus Pengembangan Silabus dan Penilaian Mata Pelajaran Biologi. Jakarta.

[2] Depdiknas, 2003b. Pendekatan Kontekstual (Contextual Teaching and Learning, CTL). Jakarta.

[3] Dryden, G and J. Vos, 2000. Revolusi Cara belajar: Keajaiban Pikiran. Penerbit Kaifa, Bandung.

[4] Galus, P.J. 2002. Classroom Composting, Creating Compost Using Inquiry-Based Design. The Science Teacher. 69 (9) : 26-30.

[5] Gwen N, G. Kunz., R. Levy., D. Harwood., D. Carlson. 2008. The Impact of a Field-Based, Inquiry-Focused Model of Instruction on Preservice Teachers' Science Learning and Attitudes. Electronic Journal of Science Education Vol. 12, No. 2. (Online) : www.ejmste.com. Diakses, 25 Maret 2008.

[6] Harjosoemantri, K. 2003. Perlu Pendekatan Integratif Dalam Pendidikan Lingkungan, Majalah Gerbang, Edisi 12 Th. II.

[7] Hardland, K. 2003. The Real Fish Story, Student Raise Salmon and Ecological

Awarenes. The Science Teacher. 70 (5) : 24-27.

[8] Hayes, C. 2004. Praise Acres Project: An Idea From a Local Resident Turns Into a

Project That Enhances High School Curriculum. The Science Teacher. 71 (5) :

34-35.

[9] Jufri, A.W. 2007. Pengaruh Implementasi Perangkat Pembelajaran Biologi

Berbasis Inkuiri Melalui Strategi Kooperatif terhadap Keterampilan

Berpikir Kritis, Sikap, dan Hasil Belajar Kognitif Siswa. (Disertasi)

Universitas Negeri Malang.

[10] Longgena, G. 2003. Belum Serius Perhatian Pemerintah Terhadap Pendidikan

Lingkungan, Majalah Gerbang, Edisi 12 Th. II.

[11] Messina., L. \& P.B.Blanchard. Wetlands Work: Students Use Classroom Lessons to Help Their Local Environment, The Science Teacher. 71 (5) : 44-45.

[12] Mulyasa, 2003. Kurikulum Berbasis Kompetensi, Konsep, Karakteristik, Implementasi dan Inovasi. Remaja Rosdakarya, Bandung.

[13] Setiawan, B.B. 2004. Pendidikan Lingkungan Disesuaikan Dengan Isu Lokal, Majalah Gerbang, Edisi 12 Th. III.

[14] Thomas, J.W., Mergendoller, J.R., and A. Michaelson (1999). Project-Based Learning: A Handbook for Middle and High School Teachers. Buck Institute for Education. (Online): http://www.bie.org. Diakses tanggal 25 Januari 2005.

[15] Thomas, J.W. 2000. A Review of Research on ProjectBased Learning. (Online) : http://www. autodesk.com/ foundation: Diakses, 18 September 2004. 